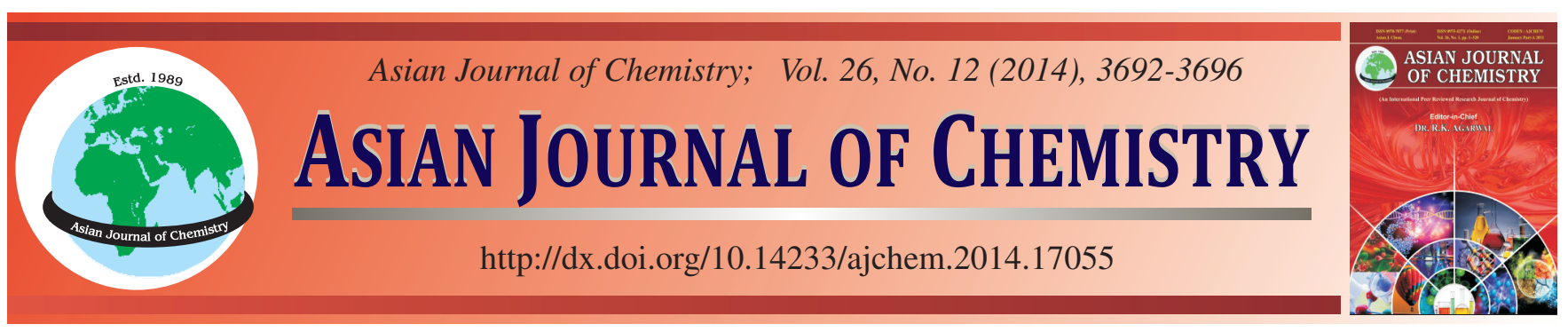

\title{
Standardization and in vitro Cytotoxic Studies on Narasimha lehiyam: A Potent Anticancer Siddha Drug †
}

\author{
N. Ravichandran ${ }^{*}$, P. Rajalakshmi, C. Davidraj, K.P. Arun and P. Brindha
}

Centre for Advanced Research in Indian System of Medicine, SASTRA University, Thanjavur-613 401, India

*Corresponding author: E-mail: brindha@ carism.sastra.edu

\begin{abstract}
Cancer is one of the major killing disease, worldwide 10 million people were diagnosed every year with cancer. Chemical and radiation therapy are often recommemded treatments for cancer which often leads to a variety of side effects, hence herbal drugs are resolved to as an alternative therapy due its lesser side effects. But herbal drugs need standardization and validation studies. Narasimha lehiyam a herbal based Siddha formulation used to treat cancer, skin diseases, ulcer, leprosy, infectious diseases, glandular enlargement, dropsy, paralysis, diabetes, sinusitis, piles and pistula. The present paper was studied the standardization and validation point of view. Attempts were made to determine the quality parameters for this siddha formulation which include determination of organoleptic and physico chemical constants such as loss on drying, ash values and specific gravity. Besides total solid contents, fat contents, reducing sugars, alkaloids flavonoids, phenols, saponins and tannins were also estimated. The compounds present in the Narasimha lehiyam were identified using LC-MS/MS and GC-MS. The in vitro anticancer potential evaluated using MTT assay, the data of the results obtained were encouraging.
\end{abstract}

Keywords: Narasimha lehiyam, Calcium oxalate crystals, Resin Containing cells, Micromorphology, LC-MSMS and MTT assay. |

\section{INTRODUCTION}

Quality assessment is essential for the international acceptance and recognition of herbal based medicines ${ }^{1,2}$. One of the major problems faced by the herbal industries is the non availability of standard quality control parameters for individual herbals and formulations. Quality parameters to determine the quality include botanical characterization, determining physical properties, identifying chemical constituents and evaluating pharmacological parameters ${ }^{3,4}$. WHO encourages, recommends and promotes traditional/herbal medicine in health care programme because of their low cost, safety and affordability ${ }^{5}$. Narasimha lehiyam (NL) a polyherbal formulations contains 21 ingredients like Asparagus racemosus Willd. (tuber), Sesamum indicum L. (seeds), Tribullus terrestris L. (fruits), Tinospora cordifolia (Willd.) Hook. F. Thomas (sugar), Ipomoea digitata L. (tuber), Plumbago rosea L. (root), Semecarpus anacardium L. (seed), Zingiber officinale Rosc. (rhizome), Piper nigrum L. (fruits), Piper longum L. (fruits), Myristica fragrans Hout. (seed and ariel), Syzygium aromaticum (L.) Merrill \& Perry (flower bud), Strychnus potatorum L. (seed), Glycyrrhiza glabra L. (root), Coptis teeta Wall. (tuber), Elettaria cardamomum Maton (fruit), Datura strominium L. (seeds), sugar, honey and ghee ${ }^{6,7}$. The Narasimha lehiyam is used as an anticancer drug, as an immunomodulator and aphrodisiac, also used to give strength to human body. The major phytoconstituents present in the Narasimha lehiyam are piperine, strchynine, brucine, plumbagine, zingiberol, zingiberene, bisobolene, gingerosol, glycyrhyzin, glycyrrhizic acid, asparagin, glycyrrhetinic acid. The Narasimha lehiyam was procured from market and used for standardization studies.

\section{EXPERIMENTAL}

Organoleptic characterization: Narasimha Lehiyam was purchased from the local market of Thanjavur, Tamil Nadu, India. For organoleptic characterization the colour, taste, odour and consistency were tested according to the methods described in Ayurvedic pharmacopeia.

Microscopic characterization: Small amount of sample was treated with chloral hydrate, phloroglucinol, iodine potassium iodide (IKI), Sudan Black B and oil red. The type and shape of crystals, fibres, xylem vessels elements, starch grains, stone cells, starch grains, trichomes, parenchyma cells and presence of oil globules, aleurone grains were detected by using Carl Zeiss microscope and the photomicrographs were taken with the help of ProgRes software and digital camera ${ }^{8}$. 
Analysis of physicochemical constants: Physicochemical constants such as ash values, extractive values, loss on drying, $\mathrm{pH}$, specific gravity were analyzed as per Ayurvedic pharmacopoeia ${ }^{9}$ and the results were tabulated.

Preliminary and presented phytochemical analysis: Preliminary phytochemical analysis of different extracts of Narasimha lehiyam was carried out. Narasimha lehiyam extracted using hexane, ether, ethyl acetate, ethanol and water. All the extracts were used for the preliminary phytochemical studies for the qualitative analysis of steroids, glycosides, saponins, alkaloids, flavonoids, tannins, proteins, amino acids and carbohydrates ${ }^{10}$.

Reducing sugars, alkaloids, flavonoids, phenolic content, saponins and tannins were estimated as per standard textual procedure $^{10-13}$.

GC-MS analysis of Narasimha lehiyam: PerkinElmer Clarus 500 was used for GC-MS analysis. Elite-5MS Capillary Column was used (5\% phenyl $95 \%$ dimethylpolysiloxane), the column length is $30 \mathrm{~m}$ and the column id: $250 \mu \mathrm{m}$. Turbomass ver 5.2.0 software was used.

GC Conditions: Oven Program: $50{ }^{\circ} \mathrm{C} @ 8{ }^{\circ} \mathrm{C} / \mathrm{min}$ to $200{ }^{\circ} \mathrm{C}$ (2 min) @ $8{ }^{\circ} \mathrm{C} / \mathrm{min}$ to $280^{\circ} \mathrm{C}$ (10 min). Injector temp.: $280^{\circ} \mathrm{C}$. Carrier gas: Helium @ flow rate $1 \mathrm{~mL} / \mathrm{min}$, Split ratio: $1: 10$.

MS Conditions: Mass range : 40-600 amu, type of ionization: electron ionization (EI), electron energy : $70 \mathrm{eV}$, transfer line and source temperature: 200 and $150{ }^{\circ} \mathrm{C}$, library : NIST 2005. Sample injected: $1.0 \mu \mathrm{L}$, the fragments mass value, retention time were analyzed and compared the data available in NIST library.

Compounds identification by LC-MS/MS: Polar and semi polar molecules of Narasimha lehiyam methanolic extract were separated and identified using LC-MSMS. Methanolic extract was chromatographed over $\mathrm{C}_{18}$ RP column (Acclaim $120 \AA$ A $2.1 \mathrm{~mm} \times 150 \mathrm{~mm}, 3.0 \mu \mathrm{m}$, Dionex, USA). Eluted compounds were then identified using MS and their respective MSMS pattern. UHPLC was conditioned at $0.2 \mathrm{~mL} / \mathrm{min}$ flow rate, with gradient mobile system start at $1 \%$ acetonitrile for 0.2 min and $99 \%$ water (1\% acetic acid).

This was then brought to $75 \%$ acetonitrile at 16 th $\min$ and then reaching at $100 \%$ acetonitrile at 19 th $\min$ to $5 \%$ acetonitrile at $21 \mathrm{st}$ min and was maintained at same condition till run ends at $23 \mathrm{rd}$ min. Absorbance was read arbitrary at $325 \mathrm{~nm}$. Exact mass of each eluted compound and their fragmented pattern (MSMS) were identified using ESI-Q-II TOF (Bruker, Germany) at negative mode, nebulizer was set at 30.5 psi with $6.0 \mathrm{~L} / \mathrm{min} \mathrm{N}_{2}$ flow rate. Masses were analyzed in 50$1000 \mathrm{~m} / \mathrm{z}$ range, keeping capillary voltage of $4500 \mathrm{~V}$ with dry heater temperature at $280{ }^{\circ} \mathrm{C}$.

in vitro anticancer studies MTT assay: Ehrlich ascites carcinoma cell lines were cultured in 96 well plates with growth medium RPMI1640 and $10 \%$ FCS. NL (1 mg) was dissolved in $100 \mu \mathrm{L}$ of $1 \%$ DMSO. Sample was filtered through $0.45 \mu \mathrm{m}$ syringe filter. 10,000 cells $/ 100 \mu \mathrm{L}$ media were incubated with increasing concentrations of drug for $48 \mathrm{~h}$ at $37{ }^{\circ} \mathrm{C}$ in $\mathrm{CO}_{2}$ incubator with $5 \% \mathrm{CO}_{2}$. After incubation, $20 \mu \mathrm{L}$ of MTT $(5 \mathrm{mg} /$ $\mathrm{mL}$ conc.) is added and then incubated for $3 \mathrm{~h}$ at $37{ }^{\circ} \mathrm{C}$ in $\mathrm{CO}_{2}$ incubator. The purple colour precipitate was formed. $10 \mu \mathrm{L}$ of DMSO was added in all the wells to dissolve MTT formazon crystals and incubated for $10 \mathrm{~min}$ at $37^{\circ} \mathrm{C}$ in $\mathrm{CO}_{2}$ incubator. The absorbance was recorded at $590 \mathrm{~nm}^{14}$.

$$
\text { Anticancer activity }(\%)=\frac{\text { Treated sample OD }}{\text { Control OD }} \times 10
$$

\section{RESULTS AND DISCUSSION}

The organoleptic characters of the Narasimha lehiyam were studied and the following characters were observed and recorded in Table- 1 .

TABLE-1

ORGANOLEPTIC CHARACTERS OF Narasimha lehiyam

\begin{tabular}{cc}
\hline Characters & Observed \\
\hline Colour & Dark brown \\
Odour & Characteristic \\
Taste & Sweet \\
Consistency & Thick solid mass \\
\hline
\end{tabular}

Salient microscopic characters of Narasimha lehiyam observed (Fig. 1) were compared with individual powder microscopic characters of few drugs which are used to prepare the Narasimha lehiyam as per Ayurvedic Pharmacopoeia. Calcium oxalate crystals and prism shaped calcium oxalate, lignified fibers oil globules, pitted and reticulate xylem vessels, sclereids, trichomes and starch grains were observed in Narasimha lehiyam. The above results are revealed that the Narasimha lehiyam contains all the tested ingredients as given in Table-2.

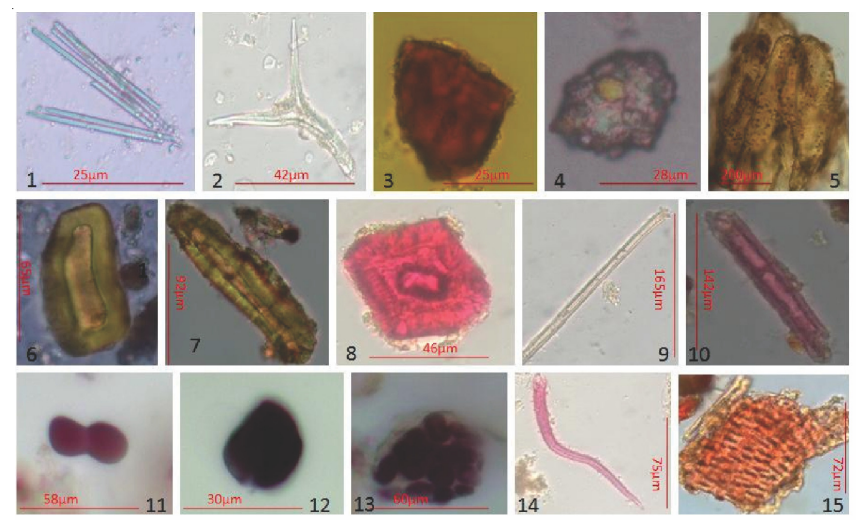

1. Acicular calcium oxalate crystals, 2. Forked sclereids, 3 . Tannin content, r. Rosette calcium crystal, 5. Parenchyma cells with starch grains, 6, 7. Elongated sclereids, 8. Isoadiametric stone cells, 9. Aseptate fibre, 10. Septate fibre, 11. Compound startch grain, 12. Simple starch grain, 13. Parenchyma cells with starch grains, 14. Lignified trichome, 15. Pitted xylem vessel

\section{Fig. 1. Microscopic characterization of Narasimha lehiyam}

Physico-chemical parameters of Narasimha lehiyam' like total ash, water soluble ash, acid insoluble ash, sulphated ash, hexane, ether, ethanol and water soluble extractive values, moisture content, total solid content, specific gravity and $\mathrm{pH}$ were determined the results were presented (Table-3).

Preliminary phytochemical screening: The preliminary phytochemical analysis were carried out and the results revealed the presence of phytoconstituents like steroids, alkaloids, tannin, phenols, flavonoids and saponins in Narasimha lehiyam (Table-4).

The fluorescence analysis of Narasimha lehiyam was carried to understand the chromophores of the chemical constituents present in the Narasimha lehiyam (Table-5). 


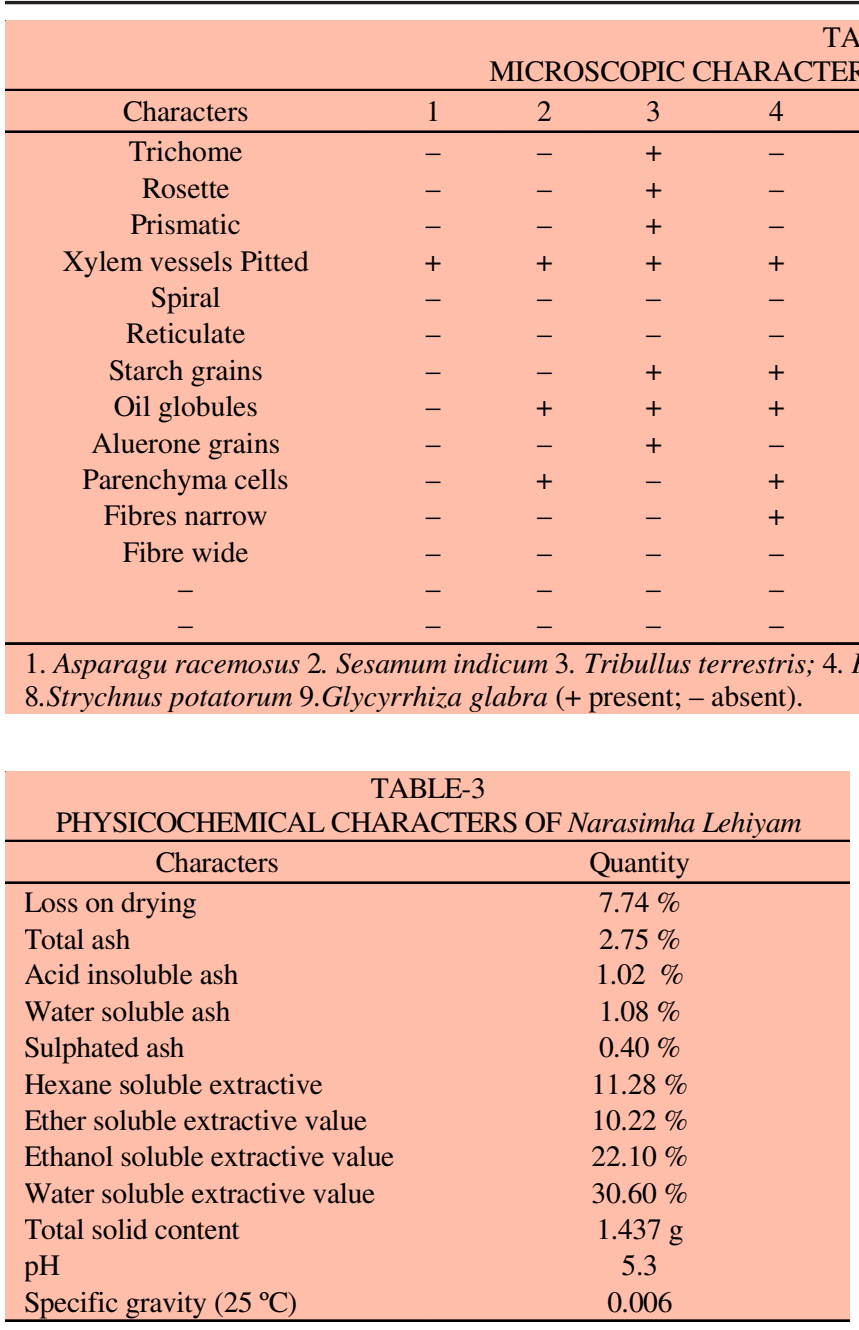

\begin{tabular}{lccccc}
\multicolumn{7}{c}{ TABLE-4 } \\
\multicolumn{7}{c}{ PRELIMINARY PHYTOCHEMICAL } \\
\multicolumn{1}{c}{ Tests for } & Hexane & Ether & Ethyl acetate & Ethanol & Water \\
\hline Phenols & - & - & + & + & + \\
Reducing sugar & - & - & - & + & + \\
Flavones & - & - & + & + & + \\
Glycosides & - & - & - & + & + \\
Saponin & - & - & - & + & + \\
Steroid & + & + & + & + & - \\
Alkaloids & - & - & - & + & + \\
Anthroquinone & + & + & - & + & - \\
Tannin & - & - & - & + & + \\
\hline
\end{tabular}

\begin{tabular}{lcc}
\multicolumn{3}{c}{ TABLE-5 } \\
\multicolumn{2}{c}{ FLUORESCENCE ANALYSIS OF Narasimha lehiyam } \\
\hline \multicolumn{1}{c}{ Treatment } & In day light & In UV light \\
\hline Sample & Green & Light green \\
Sample $+50 \% \mathrm{H}_{2} \mathrm{SO}_{4}$ & Brown & Brown \\
Sample $+1 \mathrm{~N}$ aqueous NaOH & Dark brown & Brown \\
Sample + chloroform & Yellow & Green \\
Sample + ethyl acetate & Light yellow & Green \\
Sample +hexane & Green & Green \\
Sample + acetone & Brown & Green \\
Sample + benzene & Dark green & Dark green \\
Sample +1 N HCl & Yellow & Green \\
Sample + alcohol & Green & Green \\
Sample + water & Light yellow & Green \\
\hline
\end{tabular}

Major phytoconstituents of the Narasimha lehiyam were estimated such as reducing sugar, lipids, alkaloids, flavonoids, phenol, tannin and saponins were estimated and the results are given in $\mathrm{mg} / \mathrm{g}$ (Table-6).

\begin{tabular}{cc} 
TABLE-6 \\
ESTIMATION OF PHYTOCHEMICAL CONSTITUENTS \\
\hline Constituents & Quantity $(\mathrm{mg} / \mathrm{g})$ \\
\hline Total lipids & $1.31 \pm 0.06$ \\
Total alkaloids & $0.58 \pm 0.05$ \\
Total flavonoids & $1.35 \pm 0.04$ \\
Total phenol & $1.72 \pm 0.07$ \\
Total tannin & $0.63 \pm 0.06$ \\
Total saponin & $0.89 \pm 0.07$ \\
Reducing sugar & $1.58 \pm 0.07$ \\
\hline
\end{tabular}

Heavy metal analysis of Narasimha lehiyam was carried out and they were found to be within limits as per WHO (Table-7).

\begin{tabular}{ccc}
\multicolumn{3}{c}{ TABLE-7 } \\
& \multicolumn{2}{c}{ DETERMINATION OF HEAVY } \\
& METALS IN Narasimha Lehiyam \\
\hline Metal & Content (ppm) & WHO limits (ppm) \\
\hline Mercury & 1.1 & 0.1 \\
Lead & BDL & 10 \\
Cadmium & BDL & 1 \\
\hline
\end{tabular}

The microbial contamination of the Narasimha lehiyam like total viable aerobic count, total fungal count, total enterobacteriaceae, E. coli and Salmonella were determined (Table-8).

GC-MS analysis: Compounds present in Narasimha lehiyam hexane extract identified by GC-MS are octanoic acid, hexanoic acid, nananoic acid, eugneol, decanoic acid, caryophyllene, myristicin, elemicin, hexadecanoic acid (palmitic acid), pentadecanoic acid, eicosanoic acid (arachidic acid), octadecanoic acid, oleyl alcohol and oleic acid were identified (Fig. 2).

LC-MS MS analysis: Compounds present in methanolic extract of Narasimha lehiyam were identified based on their MSMS fragmentation pattern after matching with inbuilt library and online available Mass Bank database. Vitexin, 
TABLE-8

DETERMINATION OF MICROBIAL LOAD IN Narasimha Lehiyam

\begin{tabular}{cccc}
\hline Tested microbial & Results & WHO limits & Inference \\
\hline Total viable aerobic count & $1.4 \times 10^{6} \mathrm{CFU} / \mathrm{g}$ & $<10^{7} \mathrm{CFU} / \mathrm{g}$ & Within limit \\
Total fungal count & $8.6 \times 10^{3} \mathrm{CFU} / \mathrm{g}$ & $<10^{4} \mathrm{CFU} / \mathrm{g}$ & Within limit \\
Total Enterobacteriaceae & $<10 \mathrm{CFU} / \mathrm{g}$ & $<10 \mathrm{CFU} / \mathrm{g}$ & Within limit \\
E. coli & $<10 \mathrm{CFU} / \mathrm{g}$ & $<10^{3} \mathrm{CFU} / \mathrm{g}$ & Pass \\
Salmonella $s p$ & Absent $/ 10 \mathrm{~g}$ & Absent/10 g & Pass \\
\hline
\end{tabular}

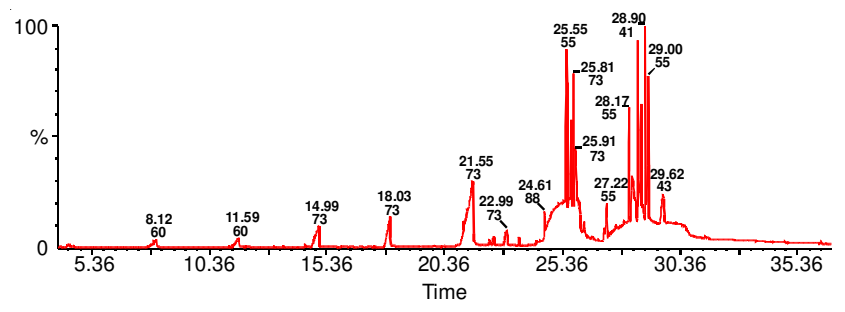

(a)
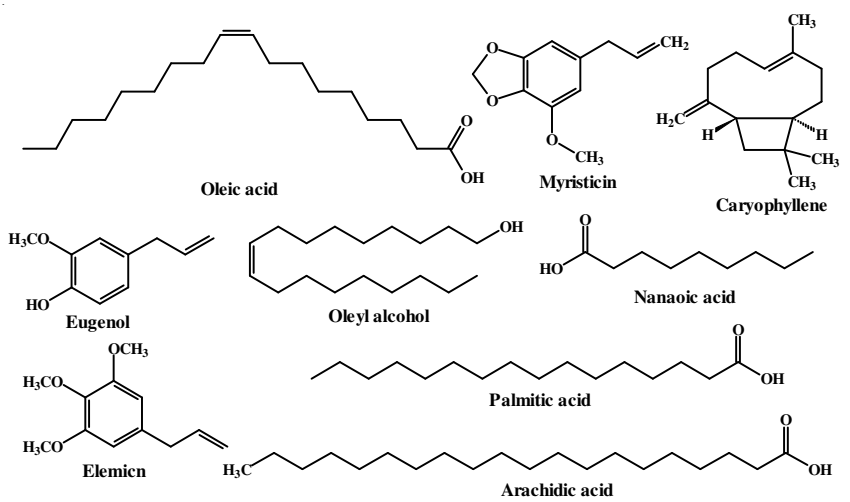

(b)

Fig. 2. (a) GCMS chromatogram of compounds identified in NL, (b) Compounds identified using GCMS of NL

brucine, glycyrrhetinic acid, glycyrrhizin and strychnine are the major compounds identified (Fig. 3). The presence of these marker compounds correlates with the observed biological activity of studied herbal formulation.
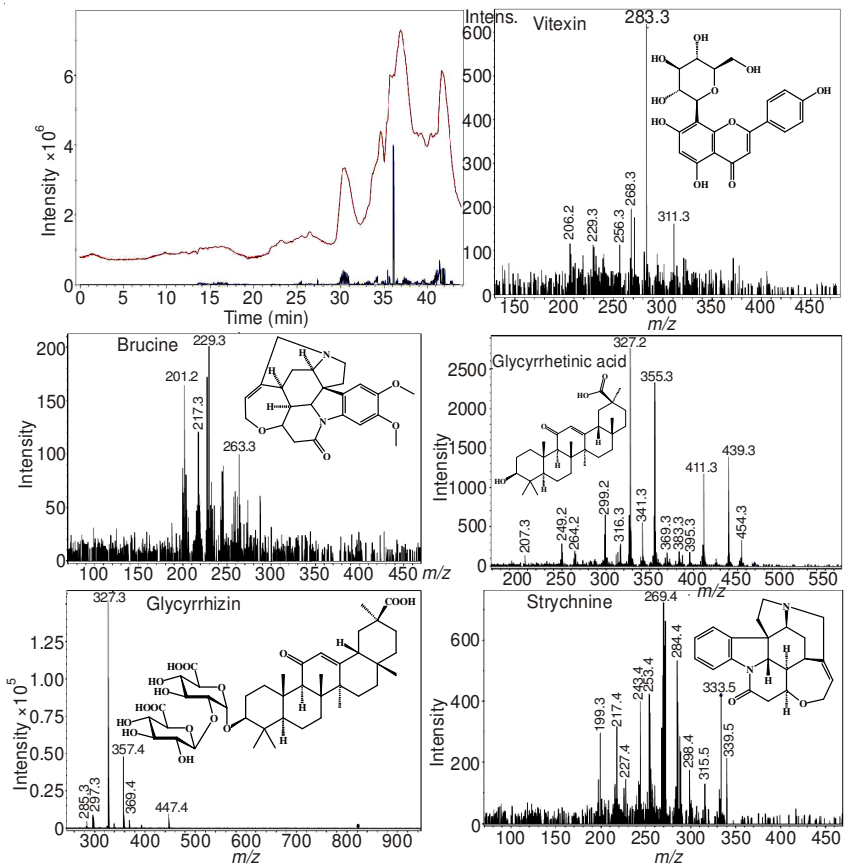

Fig. 3. Compounds identifed in LC-MS/MS ESI in vitro anticancer studies (MTT assay): The anticancer activity was evaluated for aqueous extract of Narasimha lehiyam which showed the anticancer property, the data is presented in Fig. 4. The $\mathrm{IC}_{50}$ value of the Narasimha lehiyam was $68.53 \mathrm{mg} / \mathrm{mL}$. This result showed that the in vitro anticancer potential of the Narasimha lehiyam was dose dependent as higher concentration of the lehiyam, showed higher anticancer activity (Fig. 2). The anticancer activity may be due to the presence of anticancer, immunomodulators and also antioxidants herbal drugs in Narasimha lehiyam such as Tinospora cordfolia $^{15}$, Zingiber officinale ${ }^{16}$, Plumbago rosea ${ }^{17}$, Strychnus potatorum $^{18}$, Semicarpus anacardium ${ }^{19}$, Asparagus racemosus ${ }^{20}$, Tribulus trerrestris ${ }^{21}$, Sesamum indicum ${ }^{22}$, Ipomoea digitata ${ }^{23}$, Piper nigrum ${ }^{24}$, Piper longum ${ }^{25}$, Myristica fragrans $^{26}$, Sygium aromaticum $^{27}$, Glycyrrhiza glabra ${ }^{28}$, Coptis teeta ${ }^{29}$, Elettaria cardamomum $^{30}$ and Datura strominium ${ }^{31}$.

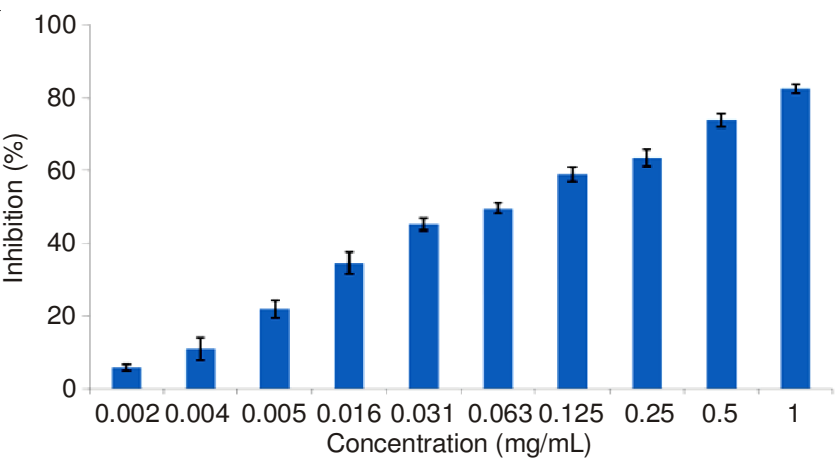

Fig. 4. in vitro anticancer activity of Narasimha lehiyam

Present study focused the quality standardization and in vitro anticancer efficacy of the Siddha formulation Narasimha lehiyam. The data obtained suggested that the tested herbal formulation might activate apoptosis because of the presence of herbals and its phytoconstituents like plumbagin, brucine, strychnine, piperine, glycyrrhizine and other constituents which play a major role in inducing apoptosis. The phytoconstituents of these ingredients not only induce apoptosis but also act as anti-oxidant by preventing the formation of free radicals and also protected from reactive oxygen species (ROS). All of the above plants and phytoconstituents act as anti cancer agents and might prevent further development of cancer by controlling the proliferation of cancer cells.

\section{Conclusion}

To conclude the standards determined in the present investigations could be useful in checking the genuineness of this Siddha herbal formulation Narasimha lehiyam. These parameters are being reported for the first time and could contribute towards the quality of Siddha formulation. The anticancer potential of this formulation was also evaluated 
using in vitro methods. Data of the results obtained suggested that Narasimha lehiyam can be used not only as an anticancer drug but also could be a good antioxidant.

\section{REFERENCES}

1. D.K. Ved and G.S. Goraya, Demand and Supply of Medicinal Plants in India In: M.P. Singh Publishers and Distributors of Scientific Books, pp. 108-115 (2008).

2. S.N. Mishra, Bhaisajya Ratnavali of Govida Das Sen, Chaukhaba Surbharati Prakasan; Varanasi, p. 780 (2007).

3. S. Panchawat, K.S. Rathore, S.S. Sisodia and R.K. Nema. Standardization and Evaluation of Herbal Drug Formulations (2010).

4. N.N. Satheesh Madhav, K. Upadhya and A. Bisht, Indian J. Physiol. Pharmacol., S3, 235 (2011).

5. WHO, The International Pharmacopeia, Quality Specifications for Pharmaceutical Substances, Excipients, and Dosage forms, World Health Organization, Geneva, edn 3 (1988).

6. S.K.M. Siddha, Ayurveda Company (India) Ltd. Therapeutic Index, SKM Siddha, Erode, Tamil Nadu, India, edn 12, p. 67 (2010).

7. S. Veeraperumal Pillai, Narasimha lehiyam In: Nam Nattu vaithiyam (Tamil) Veeraperumal Pillai Ed. Shanmuganadha Book Depot, Chennai, India (2006).

8. K.R. Khandelwal, Practical Pharmacognosy, Techniques and Experiments, Nirali Prakashan, Pune, pp. 149-156 (2002).

9. Anonymous, Parameters for Quality Assessment of Ayurveda and Siddha Drugs, Part A CCRAS, Department of AYUSH, Govt of India, New Delhi, pp. 8-9.

10. J.B. Harborne, Phytochemical Methods, Chapman and Hall, London, p. $113(1973)$

11. G.L. Miller, Anal. Chem., 31, 426 (1959).

12. B.A. Boham and A.C. Kocipai, Pac. Sci., 48, 458 (1994).
13. E.O. Edeoga, D.E. Okwu and B.O. Mbaebi, Afr. J. Biotechnol., 4, 685 (2005).

14. T. Mosmann, J. Immunol. Methods, 65, 55 (1983).

15. G.C. Jagetia and S.K. Rao, Biol. Pharm. Bull., 29, 460 (2006).

16. S. Rahman, F. Salehin and A. Iqbal, BMC Complement. Altern. Med., 11, 76 (2011)

17. P.U. Devi, F.E. Solomon and A.C. Sharada, Indian J. Exp. Biol., 32, 523 (1994).

18. K.R. Kirtikar and B.D. Basu, Indian Medicinal Plants, International Book Distributors, Deharadun, edn 4 (1996).

19. P. Mathivadhani, P. Shanthi and P. Sachdanandam, Cell Biol. Int., 31, 1198 (2007).

20. N.S. Prakash, R. Sundaram and S.K. Mitra, Indian J. Pharmacol., 44, 732 (2012)

21. H.J. Kim, J.C. Kim, J.S. Min, M.J. Kim, J.A. Kim, M.H. Kor, H.S. Yoo and J.K. Ahn, J. Ethnopharmacol., 136, 197 (2011).

22. J. Tavakkol-Afshari, A. Brook and S.H. Mousavi, Food Chem. Toxicol., 46, 3443 (2008).

23. L.W. Bieber, Á.A. Da Silva Filho, R.M.O. Corréa Lima, A. De Andrade Chiappeta, S.C. Do Nascimento, I.A. De Souza, J.F. De Méllo and H.J. Veith, Phytochemistry, 25, 1077 (1986).

24. K. Selvendiran, J.P. Singh, K.B. Krishnan and D. Sakthisekaran, Fitoterapia, 74, 109 (2003).

25. E.S. Sunila and G. Kuttan, J. Ethnopharmacol., 90, 339 (2004).

26. Y.M. Lo, Food Sci. Nutr., 1, 1 (2013).

27. S. Banerjee and C. Kr, Carcinogenesis, 27, 1645 (2005).

28. S.G. Rathi, M. Suthar, P. Patel, V.H. Bhaskar and N.B. Rajgor, J. Young Pharm., 1, 239 (2009).

29. A. Singh, S. Dugga, N. Kaur and J. Singh, J. Nat. Prod., 3, 64 (2010).

30. B. Bhattacharjee and J. Chatterjee, Asian Pac. J. Cancer Prev., 14, 3735 (2013).

31. P. Balachandran and R. Govindarajan, Pharm. Res., 51, 19 (2005). 